
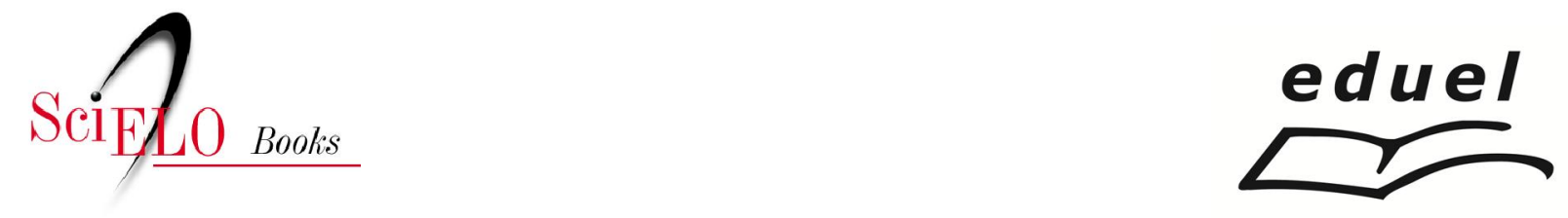

\title{
Ambiente Livre de Tabaco
}

\author{
Sandra Odebrecht Vargas Nunes \\ Márcia Regina Pizzo de Castro \\ Maria Madalena Batista de Souza Lanssoni \\ Regina Célia Rezende Machado
}

NUNES, SOV., et al. Ambiente Livre de Tabaco. In NUNES, SOV., and CASTRO, MRP., orgs. Tabagismo: Abordagem, prevenção e tratamento [online]. Londrina: EDUEL, 2011.pp. 57-64. ISBN

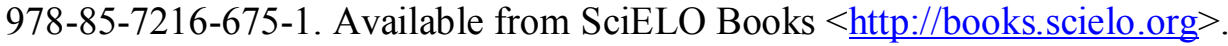

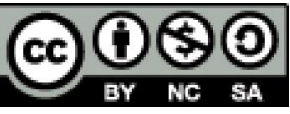

All the contents of this work, except where otherwise noted, is licensed under a Creative Commons Attribution-Non Commercial-ShareAlike 3.0 Unported.

Todo o conteúdo deste trabalho, exceto quando houver ressalva, é publicado sob a licença Creative Commons Atribuição Uso Não Comercial - Partilha nos Mesmos Termos 3.0 Não adaptada.

Todo el contenido de esta obra, excepto donde se indique lo contrario, está bajo licencia de la licencia Creative Commons Reconocimento-NoComercial-CompartirIgual 3.0 Unported. 



\section{Ambiente Livre de Tabaco}

Sandra Odebrecht Vargas Nunes Márcia Regina Pizzo de Castro Maria Madalena Batista de Souza Lanssoni Regina Célia Rezende Machado

\section{O PROGRAMA AMBIENTE LIVRE DE CIGARRO}

Todos os programas de controle do tabagismo objetivam reduzir a exposição à fumaça ambiental do tabaco dos ambientes de trabalho e unidades de saúde por meio de informação, educação, sensibilização, mobilizações políticas, medidas legislativas e econômicas favoráveis ao controle do tabagismo. (BRASIL, 2004).

Todo Ambulatório Para a Abordagem e Tratamento do Tabagismo deverá ter um ambiente 100\% livre do cigarro. Na instituição em que será implantado o ambulatório deverão ser realizados dois cursos: 1) o primeiro de abordagem breve, para sensibilizar todos os funcionários da instituição sobre os malefícios do tabagismo, do tabagismo passivo e da dependência de nicotina, e como abordar um paciente que fuma; 2) o segundo, de abordagem intensiva, com a equipe que realizará as intervenções de cessação do tabagismo. Nos cursos de treinamento, deverão ter atitudes acolhedoras e habilidades de comunicação.

Nos treinamentos, os profissionais da saúde deverão desenvolver habilidades de comunicação (perguntar, escutar e informar), usadas em três estilos (acompanhar, orientar, direcionar), para mudança de comportamento do hábito tabágico. Essas habilidades fazem parte da entrevista motivacional para explorar a percepção do paciente sobre sua situação atual e suas motivações para mudança. Dessa forma, devem-se entender as razões do paciente para a cessação do tabagismo, que muitas vezes não são as do profissional da saúde. A técnica da entrevista motivacional tem três ferramentas de habilidades de comunicação, que se unem para orientar em vez de ordenar, incentivar em vez de envergonhar, negociar em vez de ditar. O estilo de orientação é mais efetivo do 
que fazer um discurso quando se necessita mudar o comportamento. (ROLLNICK; MILLER; BUTLER ,2008).

A Organização Mundial da Saúde (OMS) recomenda, também, medidas regulamentares que atuem no setor do consumo dos produtos do tabaco, como a lei para garantir a proteção à saúde, direito e bem-estar dos não fumantes. (BRASIL, 1998). A Lei Federal N 9.294/96, regulamentada pelo Decreto N 2018 de 01 de outubro de 1996, dispõe sobre restrições ao uso e à propaganda de derivados do tabaco. (BRASIL, 1996a, 1996b). Devem ser colocados avisos escritos e orais sobre a proibição de fumar em recintos fechados onde sejam obrigatórios o trânsito ou a permanência de pessoas, considerando os dispositivos da Lei Estadual n. 14.743/2005, de 15 de junho de 2005, e as alterações introduzidas pela Lei Estadual n. 15.492/2007, de 10 de maio de 2007, do Governo do Estado do Paraná, que proíbe fumar nos recintos e edificações. (PARANÁ, 2005, 2007).

De acordo com o INCA, novas orientações devem ser adotadas pelo Brasil e pelos países que ratificaram a Tratado Internacional da Organização Mundial da Saúde, determinando que lugares públicos e ambientes de trabalho sejam 100\% livres da fumaça do tabaco, e reforçando o fato de que ventilação e filtragem do ar não são suficientes para reduzir a exposição passiva aos malefícios da fumaça do tabaco. (BRASIL, 2007). Contudo, não há métodos seguros de proteção em ambientes fechados para aqueles que não fumam. Dessa forma, a OMS entende que a única medida eficaz de proteger totalmente a saúde de não fumantes em recintos fechados é a adoção de ambientes 100\% livres do tabaco, proibindo totalmente o tabagismo em ambientes fechados.

Proibir fumar em recintos fechados onde sejam obrigatórios o trânsito ou a permanência de pessoas, precisa de avisos escritos e orais dessa proibição, de acordo com a lei 14743 de 15/06/2005, que proíbe fumar nos recintos e edificações e foi publicada no diário oficial 6998 de 16/06/2005. A instituição a ser implantado o Ambulatório Para o Tratamento da Dependência do Tabaco deverá estar sensibilizada para intervenção na estrutura física, como a remoção dos cinzeiros, proibição da venda de cigarro na instituição, 
sinalização com cartazes do ambiente livre de cigarros, normatizar as ações de controle do tabagismo, programar ações educativas e de divulgação, apoiar o funcionário fumante no processo de cessação de fumar e formar uma comissão, com profissionais das diversas áreas, para o controle do tabaco na instituição.

De acordo com estudos científicos, não há métodos seguros de proteção em ambientes fechados para aqueles que não fumam, dessa forma, segundo o INCA, a Organização Mundial da Saúde (OMS) entende que a única medida eficaz de proteger totalmente a saúde de não fumantes em recintos fechados é a adoção de ambientes $100 \%$ livres do tabaco, proibindo totalmente o tabagismo em ambientes fechados.

O Programa Ambiente Livre de Cigarro deve ser implantado porque o tabagismo é o maior fator isolado de adoecimento e morte. Principal causa de morte evitável em todo o mundo, o tabagismo causa, somente no Brasil, cerca de 200 mil mortes por ano. Da mesma forma, o tabagismo passivo causa males que vão de irritação nos olhos, tosse, dor de cabeça e aumento dos problemas alérgicos e cardíacos, até efeitos de médio e longo prazo. Os fumantes passivos têm um risco $23 \%$ maior de desenvolver doença cardiovascular e $30 \%$ mais chances de ter câncer de pulmão. Têm também mais propensão à asma, redução da capacidade respiratória, $24 \%$ a mais de chances de infarto do miocárdio e maior risco de arteriosclerose. (BRASIL, 2007).

Segundo o Instituto Nacional do Câncer (INCA), os trabalhadores, em geral, passam $80 \%$ do tempo em ambientes fechados, e o tabagismo causa a poluição tabagística ambiental. A Organização Internacional do Trabalho (OIT) calcula que pelo menos 200 mil trabalhadores morrem, a cada ano, devido à exposição à fumaça ambiental do tabaco no trabalho.

A poluição decorrente da fumaça dos derivados do tabaco em ambientes fechados é denominada de fumaça ambiental do tabaco (FAT). O indivíduo, mesmo que não sinta o incômodo pela fumaça, deve ser orientado quanto aos riscos da exposição a esse tipo de poluição, que pode causar câncer, doenças respiratórias e cardiovasculares, entre outras. 
Os dois componentes principais da fumaça ambiental do tabaco são a fumaça inalada pelo fumante, chamada de corrente primária, e a fumaça que sai da ponta do cigarro, a corrente secundária. Esta última é o principal componente da FAT, formada em $96 \%$ do tempo total da queima dos derivados do tabaco.

As substâncias como a nicotina, o monóxido de carbono, a amônia, o benzeno, as nitrosaminas e outros carcinógenos podem ser encontrados em quantidades mais elevadas na corrente secundária. Isso porque não são filtrados, e também devido ao fato de que os cigarros queimam em baixa temperatura, tornando a combustão das substâncias incompleta.

Segundo a OMS, as razões que devemos considerar ao propor ambientes sem fumaça do tabaco são (BRASIL, 2007):

- Tabaco mata e provoca doenças graves;

- Um ambiente 100\% livre de tabaco protege totalmente a população dos riscos graves da exposição ao fumo desta substância;

- Direito ao ar puro faz parte dos Direitos Humanos;

- $\quad$ Estatísticas revelam que a proibição de fumar é apoiada tanto por fumantes como por não fumantes;

- Ambientes sem fumaça de tabaco são tão bons para negócios como para famílias com crianças;

- Ambientes sem fumaça dão aos fumantes que estão tentando deixar de fumar um incentivo para fazê-lo;

- Ambientes sem fumaça ajudam a prevenir, principalmente os mais jovens, de se iniciarem como fumantes.

A implantação de uma política por um ambiente livre do tabaco. decorrente das evidências consideráveis que a exposição à fumaça ambiental do tabaco causa câncer em serem humanos. Os prejuízos à saúde da fumaça ambiental em não fumantes são: câncer de pulmão, infarto do miocárdio, função pulmonar reduzida, irritação dos olhos, congestão nasal e tosse, infecção do trato 
respiratório no primeiro ano de vida, asma e síndrome da morte súbita do lactente. (BENOWITZ, 1997).

Os profissionais de saúde são modelos de comportamento e a unidade de saúde é uma vitrine de promoção à saúde Há uma crescente demanda por parte dos fumantes para receberem apoio para deixar de fumar e o tratamento do fumante depende da estrutura de saúde e de seus profissionais.

O programa não tem como objetivo perseguir fumantes, e sim apoiá-los no processo de cessação de fumar, e consequentemente na preservação da saúde e qualidade de vida destas pessoas.

O programa deve procurar envolver fumantes nas suas atividades a ter atitudes agregadoras, não conflitantes.

Interessante envolver os ex-fumantes aos grupos de apoio, além de encorajar os novos participantes são estimulados a manterse em abstinência.

\section{CONSEQUÊNCIAS DO TABAGISMO PASSIVO}

O tabagismo passivo pode contribuir para morte por câncer de pulmão e doença arterial em não fumantes. Entre as crianças, o tabagismo passivo é implicado na síndrome de morte súbita infantil, no baixo peso ao nascer, em infecções crônicas do ouvido médio e em doenças respiratórias (asma, bronquite e pneumonia). A exposição involuntária ao tabagismo passivo permanece um risco comum à saúde pública, que pode ser prevenido com as políticas reguladoras adequadas. (SADOCK; SADOCK, 2007).

Fumantes passivos também adoecem em consequência do cigarro, e as crianças e os idosos são as principais vitimas. Os efeitos da poluição tabagística ambiental em fumantes passivos podem ser imediatos, a médio ou a longo prazo, como: irritação nos olhos; tosse; dor de cabeça; aumento dos problemas alérgicos, principalmente das vias respiratórias; e aumento dos problemas cardíacos. Pesquisas indicam um risco $23 \%$ maior de desenvolvimento de doença cardiovascular, 30\% mais chances de desenvolvimento de câncer 
de pulmão e $24 \%$ a mais de chances de infarto do miocárdio, além da redução da capacidade funcional respiratória, maior risco de aterosclerose, maior propensão à asma e maior número de infecções respiratórias, asma e doença cardiovascular em crianças. Filhos de gestantes que fumam podem nascer com baixo peso, sofrer aborto espontâneo ou morrer ao nascer. (BRASIL, 2007).

\section{AÇÕES EDUCATIVAS PARA O AMBIENTE LIVRE DE CIGARRO}

Um programa Ambiente Livre de Cigarro deve ser calcado em ações educativas para disseminar informações na comunidade, tornar os ambientes livres de tabaco e promover a cessação de fumar. O programa tem buscado potencializar essas ações por meio da mobilização de ações comunitárias, legislativas e econômicas que criem um ambiente social favorável à redução de consumo do tabaco.

As ações educativas são dirigidas a diferentes grupos-alvo, e têm como objetivos: 1) socializar as informações científicas sobre os malefícios do tabaco, incluindo o tabagismo passivo, sobre dependência do tabaco e cessação de fumar, 2) informar sobre a legislação para o controle do tabaco existente no Brasil e mobilizar seu cumprimento, 3) mobilizar o apoio da sociedade brasileira, sobretudo dos formadores de opinião, 4) estimular mudanças de comportamento entre formadores de opinião. (BRASIL, 2004). Além disso, realizar campanhas educativas na comunidade para reflexão sobre o combate ao tabagismo no Dia Mundial sem Tabaco, em 31 de maio, e no Dia Nacional de Combate ao Fumo, em 29 de agosto.

Ambientes livres do tabaco previnem a mortalidade e a morbidade, e os passos para realizá-los estão sumarizados no quadro 5 . 


\begin{tabular}{|c|c|}
\hline 1 & $\begin{array}{l}\text { Comprometimento dos dirigentes, por meio da criação de uma política institucional de } \\
\text { ambientes livres de tabaco (sugestão: elaborar um termo de compromisso para oficializar } \\
\text { a implantação do Ambiente Livre de Tabaco, com a participação ativa dos funcionários e } \\
\text { gerentes); }\end{array}$ \\
\hline 2 & $\begin{array}{l}\text { Sensibilização dos diversos setores da instituição para adesão e cumprimento da } \\
\text { política; }\end{array}$ \\
\hline 3 & $\begin{array}{l}\text { Identificar o perfil dos fumantes e não fumantes das instituições através de } \\
\text { pesquisa/questionário. Apresentar e discutir resultados com os funcionários; }\end{array}$ \\
\hline 4 & $\begin{array}{l}\text { Oferecer tratamento ou referência de locais públicos ou privados para os funcionários que } \\
\text { desejarem parar de fumar; }\end{array}$ \\
\hline 5 & Sinalizar a proibição nas dependências e veículos da instituição; \\
\hline 6 & Retirar cinzeiros; \\
\hline 7 & Monitorar, avaliar e acompanhar o pr \\
\hline
\end{tabular}

Quadro 5- Passos sugeridos para implantar um ambiente livre de tabaco.

As áreas compartilhadas por fumantes e não fumantes, num mesmo ambiente interno, não protegem adequadamente os não fumantes das toxinas contidas na fumaça dos cigarros. Como o sistema de ar condicionado é comum a todos, uma área de fumantes numa determinada parte do prédio provoca poluição do ar no prédio todo. Além disso, as restrições parciais ao tabagismo não resultam em diminuição do consumo de produtos de fumo, porque fumar continua relativamente fácil para o fumante. Por outra parte, quando $100 \%$ dos ambientes nos locais internos de trabalho estão livres do tabagismo, há uma queda de quase 30\% no tabagismo entre os fumantes. (BRASIL, 2004). 


\section{REFERÊNCIAS}

BENOWITZ, N. Tabaco. In: BENNETT, C.; PLUM, F. Cecil. Tratado de Medicina Interna. 20.ed. Rio de Janeiro: Guanabara Koogan, 1997. p.3943.

BRASIL. Lei Federal n 9294 de 15 de julho de 1996. Dispõe sobre as restrições ao uso e à propaganda de produtos fumígeros, bebidas alcoólicas, medicamentos, terapias e defensivos agrícolas, nos termos do $\S 4^{\circ}$ do art. 220 da Constituição Federal. Diário Oficial [da República Federativa do Brasil], Brasília, 16 jul. 1996a.

Decreto $n^{\circ} 2018$ de 1 de outubro de 1996. Regulamenta a Lei $\mathrm{n}^{\circ}$ 9.294, de 15 de julho de 1996, que dispõe sobre as restrições ao uso e à propaganda de produtos fumígenos, bebidas alcoólicas, medicamentos, terapias e defensivos agrícolas, nos termos do $\S 4^{\circ}$ do art. 220 da Constituição. Diário Oficial [da República Federativa do Brasil], Brasília, 2 out. $1996 \mathrm{~b}$.

. Secretaria Nacional de Assistência à Saúde; Instituto Nacional do Câncer. Coordenação Nacional de Controle do Tabagismo e Prevenção Primária de Câncer (Contapp). Falando sobre tabagismo. 3.ed. Rio de Janeiro: INCA, 1998. p. 56-9.

. Ministério da Saúde. Tabaco e pobreza: um círculo vicioso. Brasília, 2004.

INSTITUTO NACIONAL DO CÂNCER (INCA). Ambiente livre do fumo é direito de todos. Disponível em: <http://www.inca.gov.br/releases/ press_release_view.asp? ID=1491>. Acesso em: 29 ago. 2007.

PARANÁ. Lei Estadual n 14743, de 15 de junho de 2005. Proíbe fumar nos recintos e edificações que especifica e adota outras providências.Assembléia Legislativa do Estado do Paraná. Diário Oficial [do Estado do Paraná], Curitiba, n. 6998, 16 jun. 2005.

Lei Estadual n $n^{0} 15492$, de 9 de maio de 2007. Altera dispositivos da Lei 14743, de 15 de junho de 2005, que dispõe sobre proibição de fumar em recintos públicos, conforme especifica. Diário Oficial [do Estado do Paraná], Curitiba, n. 7468, 10 maio 2007.

ROLLNICK, S.; MILLER,W.; BUTLER,C. Entrevista Motivacional no cuidado da saúde: Ajudando pacientes a mudar o comportamento. Porto Alegre: ARTMED, 2008.

SADOCK, B. J.; SADOCK, V. A. Compêndio de psiquiatria: Ciência do Comportamento e Psiquiatria Clínica. 9. ed. Porto Alegre: Artmed, 2007. 